\title{
Níveis protéicos na ração de frangos de corte na fase de crescimento
}

\author{
Hellen Fernanda Nocciolli Sabino(1), Nilva Kazue Sakomura ${ }^{(1)}$, Rafael Neme ${ }^{(1)}$ e Ednardo Rodrigues Freitas ${ }^{(1)}$ \\ (1)Universidade Estadual Paulista, Dep. de Zootecnia, Via de Acesso Prof. Paulo Donato Castellane s/no , CEP 14 884-900 Jaboticabal, SP. \\ E-mail: hellensabino@hotmail.com, sakomura@fcav.unesp.br
}

\begin{abstract}
Resumo - O objetivo deste trabalho foi determinar o nível mínimo de proteína bruta para atender às exigências nutricionais de frangos de corte Hubbard, machos e fêmeas, na fase de crescimento. Oitocentos e oitenta pintos machos e fêmeas de 22 a 42 dias de idade foram distribuídos ao acaso em esquema fatorial $5 \times 2$ (níveis de proteína bruta x sexos), com quatro repetições de 22 aves. Os níveis de proteína testados foram 15\%, 17\%, 19\%, 21\% e $23 \%$. Houve efeito quadrático dos níveis de proteína no ganho de peso e na conversão alimentar dos machos. Em relação às fêmeas, o efeito foi quadrático no ganho de peso e linear na conversão. A relação entre o rendimento de carcaça e o nível de proteína bruta da ração foi linear e independente do sexo. O consumo de ração, a gordura abdominal e o rendimento de peito foram influenciados apenas pelo sexo. Recomenda-se $21,70 \%$ de proteína bruta para os machos e 19,00\% para as fêmeas, na fase de crescimento.
\end{abstract}

Termos para indexação: níveis de proteína bruta, desempenho.

\section{Dietary protein levels on the growing broiler diets}

\begin{abstract}
The objective of this work was to determine crude protein levels on diet of males and females broilers from 22 to 42 days of age. Males (440) and females (440) broilers chickens Hubbard were distributed in a completely randomized design, in order to study five crude protein levels $(15 \%, 17 \%, 19 \%, 21 \%$ and $23 \%)$ in a factorial arrangement. For male broilers, the protein levels had a quadratic effect on weight gain and feed:gain ratio. For females, the effect of protein levels was quadratic on weight gain and linear on feed:gain ratio. The dietary protein levels affected linearly the yield carcass for both sex. The females had higher abdominal fat and breast percentage than the males. The protein level recommended for male broilers is $21.70 \%$ and for females is $19.00 \%$.
\end{abstract}

Index terms: broiler chickens, dietary crude protein levels, performance.

\section{Introdução}

$\mathrm{O}$ atendimento das exigências protéicas, ou melhor, das exigências em aminoácidos para aves está associado ao custo da alimentação uma vez que a proteína é o segundo nutriente mais caro da ração e representa de $40 \%$ a $45 \%$ do custo total da ração (Sakomura \& Silva, 1998). Por isso, a redução protéica tem sido vista como uma das vias de possível melhoria dos custos de produção e o nível protéico da ração passou a ser definido como o nível ótimo para responder às necessidades da ave em aminoácidos, considerando o custo dos ingredientes usados na formulação e o valor das carnes produzidas. Entretanto, ainda é possível encontrar formulações de rações para aves com níveis de proteína bruta muito elevados.
Aminoácidos industriais tais como lisina, metionina, treonina e triptofano têm significativa participação na aplicabilidade do conceito de proteína ideal para aves. Também têm viabilizado pesquisas a fim de reduzir o nível de proteína bruta nas rações e atender às exigências nutricionais de aminoácidos com suplementação. Assim, é possível evitar o excesso de aminoácidos, aumentar a eficiência de utilização da proteína e reduzir a poluição ambiental em função de uma menor excreção de nitrogênio (Deschepper \& De Groote, 1995; Diambra \& McCartney, 1995; Schutte \& Pack, 1995; Hurwitz et al., 1998).

O objetivo deste trabalho foi determinar o nível mínimo de proteína bruta para atender as exigências nutricionais de frangos de corte machos e fêmeas na fase de crescimento. 


\section{Material e Métodos}

O experimento foi realizado no Setor de Avicultura da Faculdade de Ciências Agrárias e Veterinárias, Universidade Estadual Paulista, Jaboticabal, SP.

No período de 1 a 21 dias de idade, as aves foram criadas em um galpão convencional num total de 21 aves por boxe. As aves foram alimentadas com ração inicial formulada à base de milho e soja, segundo as exigências nutricionais propostas por Rostagno et al. (1996). Durante esse período, ração e água foram oferecidas à vontade.

Aos 21 dias de idade, as aves foram sexadas e pesadas individualmente. Com base no peso foram distribuídas entre os tratamentos para que as parcelas tivessem pesos médios semelhantes.

Foram utilizados 880 frangos de corte machos e fêmeas, da linhagem Hubbard, distribuídos em um delineamento inteiramente casualizado em esquema fatorial $5 \times 2$ (níveis de proteína bruta x sexos), com quatro repetições de 22 aves.

$\mathrm{Na}$ fase experimental (22 a 42 dias), as exigências nutricionais foram atendidas para todos os nutrientes segundo Rostagno et al. (1996), com exceção dos níveis protéicos. Foram formuladas uma ração de diluição $(2,627 \%$ PB) e uma ração com o maior nível de proteína bruta $(\mathrm{PB})$ a ser avaliado (23\% PB) (Tabela 1). Os demais níveis de proteína foram obtidos pela mistura dessas rações, ou seja: $15 \%$ PB $(60,732 \%$ da ração de $23 \% \mathrm{~PB}+39,268 \%$ da ração diluição); $17 \%$ PB $(70,549 \%$ da ração de $23 \% \mathrm{~PB}+29,451 \%$ da ração diluição); $19 \% \mathrm{~PB}(80,366 \%$ da ração de $23 \% \mathrm{~PB}+19,634 \%$ ração diluição) e $21 \% \mathrm{~PB}(90,183 \%$ da ração de $23 \% \mathrm{~PB}+9,817 \%$ da ração diluição).

Durante o período experimental, as aves receberam ração e água à vontade e diariamente foram registradas as temperaturas máxima e mínima do interior do galpão.

Foram avaliados o ganho de peso (g/ave), o consumo de ração (g/ave), o consumo de proteína (g/ave), a conversão alimentar ( $\mathrm{kg}$ de ração consumida/ $\mathrm{kg}$ de ganho de peso) e a conversão protéica (kg de proteína consumida/kg de ganho de peso). Aos 42 dias de idade, quatro aves de cada repetição, com peso próximo ao peso médio obtido na repetição, foram selecionadas e, após jejum de 12 horas, foram abatidas para avaliar o rendimento de carcaça e de peito (\%) e a porcentagem de gordura abdominal.

A análise estatística dos dados foi realizada pela análise de variância utilizando procedimento GLM (SAS
Institute, 1996) para um modelo fatorial e as médias foram comparadas pelo teste de Tukey a $5 \%$ de probabilidade. Os dados foram submetidos a uma análise de regressão para obtenção da curva de respostas com o melhor ajuste.

\section{Resultados e Discussão}

O consumo de ração diferiu apenas entre os sexos, e o consumo dos machos foi significativamente maior (Tabela 2). Esse efeito já era esperado, pois os machos possuem maior potencial de crescimento e, conseqüentemente, necessitam de maior quantidade de nutrientes para que esse potencial seja maximizado. Como as ra-

Tabela 1. Composição porcentual e calculada da ração de crescimento com $23 \%$ de proteína bruta e da ração de diluição.

\begin{tabular}{lcc}
\hline Alimento & \multicolumn{2}{c}{ Ração } \\
\cline { 2 - 3 } & 23\% de proteína bruta & Diluição \\
\hline Milho & 55,09 & - \\
Farelo de soja & 28,42 & - \\
Glúten de milho (60\%) & 8,60 & - \\
Amido de milho & - & 74,82 \\
Inerte & - & 13,44 \\
Óleo vegetal & 4,069 & 4,00 \\
Calcário & 1,242 & 1,172 \\
Fosfato bicálcico & 1,556 & 2,157 \\
Sal comum & 0,419 & 0,518 \\
Mistura mineral ${ }^{(1)}$ & 0,200 & 0,200 \\
Mistura vitamínica ${ }^{(2)}$ & 0,400 & 0,400 \\
L - Lisina HCl & - & 1,323 \\
DL - Metionina 99\% & - & 0,820 \\
L - Treonina & - & 0,887 \\
L - Triptofano & - & 0,267 \\
\hline Total & 100,00 & 100,00 \\
\hline & Composição calculada \\
EM (kcal/kg) & 3.200 & 3.200 \\
Proteína bruta (\%) & 23,00 & 2,627 \\
Lisina (\%) & 1,037 & 1,037 \\
Metionina (\%) & 0,423 & 0,423 \\
Metionina + cistina (\%) & 0,812 & 0,812 \\
Treonina (\%) & 0,878 & 0,878 \\
Triptofano (\%) & 0,264 & 0,264 \\
Ca (\%) & 0,948 & 0,948 \\
P disponível (\%) & 0,399 & 0,399 \\
Na (\%) & 0,206 & 0,206 \\
\hline
\end{tabular}

(1) Cada quilograma do produto contém: ferro, $35.000 \mathrm{mg}$; cobre, $50.000 \mathrm{mg}$; manganês, $35.000 \mathrm{mg}$; zinco, $30.000 \mathrm{mg}$; iodo, $600 \mathrm{mg}$; selênio, $90 \mathrm{mg}$. (2) Cada quilograma do produto contém: vit. A, 2.300.000 UI; vit. $\mathrm{D}_{3}, 400.000 \mathrm{UI}$; vit. E, $1.800 \mathrm{mg}$; vit. $\mathrm{K}_{3}$, $300 \mathrm{mg}$; vit. $\mathrm{B}_{1}, 150 \mathrm{mg}$; vit. $\mathrm{B}_{2}, 1400 \mathrm{mg}$; vit. $\mathrm{B}_{12}, 3.500 \mu \mathrm{g}$; ácido pantotênico, $2.000 \mathrm{mg}$; ácido nicotínico, $7.000 \mathrm{mg}$; piridoxina, $250 \mathrm{mg}$; ácido fólico, $150 \mathrm{mg}$; biotina, $20 \mathrm{mg}$; colina, $125 \mathrm{~g}$; bacitracina de zinco, $125 \mathrm{~g}$; BHT, $20 \mathrm{~g}$. 
ções eram as mesmas para ambos os sexos, a ingestão de nutrientes para o crescimento foi obtida com o maior consumo.

A ingestão de proteína aumentou linearmente $\left(\mathrm{Y}=0,0488+0,0311 \mathrm{x} ; \mathrm{R}^{2}=82,31\right)$ com o aumento da proteína da ração, independentemente do sexo (Tabela 2). Entretanto, os machos ingeriram mais proteína do que as fêmeas. Como o consumo de ração não diferiu significativamente entre os tratamentos, as aves alimentadas com as rações contendo níveis mais elevados de proteína acabaram ingerindo maior quantidade desse nutriente. Da mesma forma, o maior consumo de ração resultou em maior ingestão de proteína pelos machos.

Esses resultados indicam que a maior ingestão de proteína bruta, em virtude do aumento da proteína da ração, não influenciou o consumo de ração dos frangos. Isto pode ser atribuído à suplementação dos aminoácidos essenciais metionina, lisina, treonina e triptofano, com o objetivo de evitar deficiência em rações com níveis mais baixos de proteína. Segundo Gonzales (2002), o controle do consumo de ração não é somente decorrente da quantidade de proteína bruta, mas também de sua qualidade, isto é, do balanceamento entre os aminoácidos. O grau de deficiência ou desbalanceamento de aminoácidos na ração resulta em reações variadas por parte das aves, fazendo com que o consumo de ração seja alterado (Albino et al., 1999). Avaliando rações de diferentes níveis protéicos com metionina e lisina, Lisboa \& Silva (1999) não observaram influência significativa da proteína no consumo de ração. Por sua vez, Diambra \& McCartney (1995) observaram que aves submetidas a rações deficientes em proteína tendem a aumentar o consumo para compensar tal deficiência.

Em relação ao ganho de peso, houve interação significativa entre os níveis de proteína e o sexo. A análise de regressão revelou efeito quadrático dos níveis de proteína sobre o ganho de peso dos machos $\left(\mathrm{Y}=-2,7564+0,4436 \mathrm{x}-0,0105 \mathrm{x}^{2} ; \mathrm{R}^{2}=80,80\right)$ e das fêmeas $\left(Y=-0,6972+0,2162 \mathrm{x}-0,0051 \mathrm{x}^{2} ; \mathrm{R}^{2}=45,97\right)$. Por sua vez, Lisboa \& Silva (1999) observaram que o ganho de peso aumentou linearmente com o aumento de proteína da ração.

$\mathrm{O}$ ganho de peso dos machos aumentou à medida que os níveis de proteína aumentaram, atingindo o máximo com $21,12 \%$ de proteína bruta na ração, segundo a equação obtida. Entretanto, apesar de ter sido observado o mesmo comportamento em relação às fêmeas, a confiabilidade no melhor nível de proteína bruta determinado pelo ponto de máxima pode ser questionada, uma vez que a equação obtida apresentou baixo coeficiente de determinação apesar de ter sido significativa.

Tabela 2. Desempenho de frangos de corte machos e fêmeas no período de 22 a 42 dias de idade, submetidos à rações com diferentes níveis de proteína bruta ${ }^{(1)}$.

\begin{tabular}{|c|c|c|c|c|c|c|}
\hline \multirow[t]{2}{*}{ Sexo } & \multicolumn{5}{|c|}{ Níveis de proteína bruta da ração (\%) } & \multirow[t]{2}{*}{ Média } \\
\hline & 15 & 17 & 19 & 21 & 23 & \\
\hline \multicolumn{7}{|c|}{ Consumo de ração (g/ave) } \\
\hline Macho & 3.548 & 3.620 & 3.566 & 3.580 & 3.449 & $3.553 \mathrm{a}$ \\
\hline Fêmea & 3.199 & 3.229 & 3.316 & 3.093 & 3.144 & $3.196 b$ \\
\hline Média & $3.374 \mathrm{~A}$ & $3.425 \mathrm{~A}$ & $3.441 \mathrm{~A}$ & $3.336 \mathrm{~A}$ & $3.296 \mathrm{~A}$ & \\
\hline \multicolumn{7}{|c|}{ Consumo de proteíma (g/ave) } \\
\hline Macho & 532 & 616 & 678 & 752 & 793 & $674 a$ \\
\hline Fêmea & 480 & 549 & 630 & 650 & 723 & $606 \mathrm{~b}$ \\
\hline Média $^{(2)}$ & $506 \mathrm{E}$ & $582 \mathrm{D}$ & $654 \mathrm{C}$ & $701 \mathrm{~B}$ & $748 \mathrm{~A}$ & \\
\hline \multicolumn{7}{|c|}{ Ganho de peso (g/ave) } \\
\hline Macho $^{(3)}$ & $1.505 \mathrm{aB}$ & $1.801 \mathrm{aA}$ & $1.822 \mathrm{aA}$ & $1.916 \mathrm{aA}$ & $1.880 \mathrm{aA}$ & 1.785 \\
\hline Fêmea ${ }^{(3)}$ & $1.404 \mathrm{bB}$ & $1.440 \mathrm{bAB}$ & $1.610 \mathrm{bA}$ & $1.548 \mathrm{bAB}$ & $1.557 \mathrm{bAB}$ & 1.512 \\
\hline Média & 1.454 & 1.620 & 1.716 & 1.732 & 1.719 & \\
\hline \multicolumn{7}{|c|}{ Conversão alimentar $(\mathrm{kg} / \mathrm{kg})$} \\
\hline Macho $^{(3)}$ & $2,36 \mathrm{aA}$ & $2,01 \mathrm{bB}$ & $1,96 \mathrm{aBC}$ & $1,87 \mathrm{bC}$ & $1,83 \mathrm{bC}$ & 2,00 \\
\hline Fêmea $^{(2)}$ & $2,28 \mathrm{aA}$ & $2,24 \mathrm{aA}$ & $2,06 \mathrm{aB}$ & $1,99 \mathrm{aB}$ & $2,02 \mathrm{aB}$ & 2,12 \\
\hline Média & 2,32 & 2,12 & 2,00 & 1,93 & 1,93 & \\
\hline \multicolumn{7}{|c|}{ Conversão protéica $(\mathrm{kg} / \mathrm{kg})$} \\
\hline $\operatorname{Macho}^{(3)}$ & $0,354 \mathrm{aDC}$ & $0,342 \mathrm{bD}$ & $0,372 \mathrm{aC}$ & $0,393 \mathrm{bB}$ & $0,442 \mathrm{bA}$ & 0,381 \\
\hline Fêmea $^{(2)}$ & $0,343 \mathrm{aD}$ & $0,381 \mathrm{aC}$ & $0,391 \mathrm{aC}$ & $0,420 \mathrm{aB}$ & $0,464 \mathrm{aA}$ & 0,400 \\
\hline Média & 0,348 & 0,362 & 0,382 & 0,406 & 0,443 & \\
\hline
\end{tabular}


O ganho de peso das fêmeas melhorou até o nível de $19 \%$ de proteína e nos níveis seguintes houve uma redução numérica nos resultados atingindo um platô (Tabela 2). Portanto, o nível de 19\% de proteína pode ser recomendado para fêmeas nessa fase.

Os machos ganharam mais peso que as fêmeas $(\mathrm{P}<0,05)$ em todos os níveis de proteína bruta estudados. Resultados semelhantes foram obtidos por Moran et al. (1992) e podem ser atribuídos ao maior potencial de crescimento dos machos em relação às fêmeas.

Houve interação significativa $(\mathrm{P}<0,05)$ entre os fatores estudados em relação à conversão alimentar. A análise de regressão revelou efeito quadrático dos níveis de proteína na conversão alimentar dos machos $\left(\mathrm{Y}=6,8646-0,4608 \mathrm{x}+0,0106 \mathrm{x}^{2} ; \mathrm{R}^{2}=90,77\right) \mathrm{e}$ linear na conversão alimentar das fêmeas $\left(\mathrm{Y}=2,8561-0,0387 \mathrm{x} ; \mathrm{R}^{2}=68,83\right)$.

Nos machos, a conversão alimentar melhorou à medida que os níveis de proteína aumentaram, atingindo o melhor resultado com $21,70 \%$ de proteína bruta na ração, segundo a equação obtida. Entretanto, nas fêmeas, o efeito obtido não permite determinar o melhor nível de proteína. A conversão alimentar melhorou até o nível de $19 \%$ de proteína atingindo um platô nos níveis seguintes (Tabela 2). Portanto, este nível de proteína pode ser recomendado para fêmeas nessa fase.

Uma vez que os níveis de proteína bruta não afetaram o consumo de ração, as diferenças de ganho de peso podem ser atribuídas à eficiência de utilização das rações pelas aves.

Na conversão protéica, houve interação entre os fatores estudados. A análise de regressão revelou o mesmo comportamento observado em relação aos dados de conversão alimentar. A conversão protéica dos machos variou de acordo com a equação $\mathrm{Y}=0,6605-0,0403 \mathrm{x}+$ $0,0013 x^{2}\left(R^{2}=89,39\right)$ e das fêmeas $Y=0,1318+0,0141 x$ $\left(R^{2}=91,09\right)$. Houve redução no aproveitamento da proteína para o ganho de peso com o aumento da quantidade de proteína na ração (Tabela 2). Cheng et al. (1997) também observaram que a conversão protéica piorou quando se aumentou o teor protéico da ração. Segundo Leeson (1995), a redução da eficiência do uso da proteína ocorre por causa da síntese muscular ser geneticamente controlada, havendo, portanto um limite na deposição diária de proteína, independentemente de sua ingestão.

De acordo com Sklan \& Plavnik (2002), as rações de frangos de corte devem ser formuladas para fornecer aminoácidos suficientes para a síntese protéica e o excesso destes pode resultar em queda na eficiência de utilização e aumento do requerimento dos aminoácidos essenciais.

Isto ocorre pelo fato do excesso de proteína ser catabolizado na forma de ácido úrico, havendo um custo energético para que tal processo ocorra (Leclercq, 1996 citado por Costa et al., 2001). Este custo é relativamente alto, considerando que, para incorporar um aminoácido na cadeia protéica, estima-se em torno de 4 mols de ATP e para excretar um aminoácido são gastos de 6 a 18 mols de ATP, dependendo da quantidade de $\mathrm{N}$ do aminoácido, utilizando, na excreção de $\mathrm{N}$, a energia que deveria estar sendo utilizada na manutenção corporal.

O baixo crescimento e redução na eficiência alimentar com baixa ingestão de proteína bruta podem ser atribuídos à quantidade limitada de aminoácidos essenciais ou à quantidade insuficiente de aminoácidos não essenciais (Sklan \& Plavnik, 2002). No presente trabalho, foram suplementados os aminoácidos essenciais metionina, lisina, treonina e triptofano, e os demais aminoácidos das rações foram fornecidos pelos alimentos. Dessa forma, é possível que nas rações com níveis mais baixos de proteína os aminoácidos nãosuplementados possam ter limitado o ganho de peso e piorado a conversão alimentar.

As diferenças significativas entre os resultados de conversão alimentar e protéica obtida em relação aos machos e fêmeas ficaram restritas aos níveis de 17\%, $21 \%$ e $23 \%$ de proteína bruta. Nesses níveis, os machos apresentaram melhor conversão alimentar e protéica que as fêmeas. Entretanto, no nível mais baixo de proteína estudado (15\%) os machos apresentaram piores resultados, em termos numéricos. Isso evidencia o fato de os machos serem mais exigentes em razão do maior potencial de crescimento e, portanto, serem mais prejudicados do que as fêmeas com a redução da proteína até esse nível.

O rendimento de carcaça, independentemente do sexo, foi influenciado linearmente $\left(Y=62,487+0,2444 x ; R^{2}=20,93\right)$ pelo nível de proteína bruta da dieta, mostrando que o aumento no teor de proteína aumentou o rendimento de carcaça (Tabela 3). Tais resultados diferem dos encontrados por Lisboa \& Silva (1999), que observaram diminuição linear no rendimento de carcaça com o aumento do teor de proteína da dieta. Entretanto, Olomu \& Offiong (1980) e Moran et al. (1982) não observaram efeito significativo para tal variável quando avaliaram diferentes níveis de pro- 
teína na ração de frangos de corte. Por sua vez, Salmon et al. (1983) e Cahaner et al. (1997) observaram que o rendimento de carne total aumentou com o nível de proteína da dieta final.

O excesso de deposição de gordura na carcaça é prejudicial na produção de frango de corte, pois a gordura é vista de modo desfavorável pelo consumidor e representa perda no rendimento se for removida durante a industrialização (McLeod, 1982; Leenstra, 1986). No presente trabalho, a porcentagem de gordura abdominal não foi influenciada significativamente pelos níveis de proteína bruta da dieta. Entretanto, os níveis de $15 \%$ para os machos e $15 \%$ e $17 \%$ para as fêmeas proporcionaram os maiores teores de gordura abdominal. O elevado coeficiente de variação, geralmente encontrado nas análises de gordura abdominal, pode ter influenciado os resultados obtidos. Os machos apresentaram uma redução de $29,9 \%$ na quantidade de gordura abdominal quando as aves alimentadas com $15 \%$ passaram a ser alimentadas com $23 \%$ de proteína bruta. Em relação às fêmeas a redução foi menor, passando de 4,65\% de gordura abdominal nas aves alimentadas com $15 \%$ PB para $4,17 \%$ nas aves alimentadas com $23 \%$ de proteína bruta.

Buyze et al. (1992) estudaram os efeitos da redução dos níveis de proteína de $20 \%$ para $15 \%$ e verificaram aumento nos teores de gordura abdominal depositados. Lisboa \& Silva (1999) observaram efeito linear do nível de proteína no peso de gordura abdominal, que aumentou com a diminuição do nível protéico da ração, mas não sobre a porcentagem de gordura corporal. Conforme esses autores, as rações com menores teores protéicos tornaram-se deficientes no aminoácido essencial treonina, uma vez que este não foi suplementado. Desta forma, este aminoácido pode ter limitado a síntese protéica e desta maneira os aminoácidos ficaram disponíveis para síntese de gordura.

Além disso, Roush (1983) e Sklan \& Plavnik (2002) citam que rações com baixo conteúdo protéico causam aumento na deposição de gordura nos tecidos, em razão da incapacidade da ave utilizar energia para a deposição de proteína. Como a ração não contém quantidade suficiente de proteína para ótimo crescimento, a energia extra é convertida em gordura.

Em relação ao efeito do sexo na quantidade de gordura abdominal, as fêmeas apresentaram maior porcentual de gordura em relação aos machos. Jackson et al. (1982) e Moran et al. (1992) também observaram maior quantidade de gordura nas fêmeas.

Em condições de deficiência nutricional, principalmente déficit de aminoácidos essenciais, a musculatura do peito é um dos parâmetros afetados, como descreve Fischer (1994). Neste trabalho, a porcentagem de peito não foi influenciada pelos níveis de proteína bruta da dieta, indicando que, mesmo nos menores níveis protéicos, houve fornecimento satisfatório de aminoácidos essenciais. Entretanto, houve efeito significativo em relação ao sexo, ou seja, as fêmeas tiveram um maior porcentual de peito que os machos, confirmando os resultados de Moran et al. (1992) e Lisboa \& Silva (1999).

Tabela 3. Características de carcaça de frangos de corte, machos e fêmeas, submetidos à rações com diferentes níveis de proteína bruta, no período de 22 a 42 dias de idade ${ }^{(1)}$.

\begin{tabular}{|c|c|c|c|c|c|c|}
\hline \multirow[t]{2}{*}{ Sexo } & \multicolumn{5}{|c|}{ Níveis de proteína bruta da ração (\%) } & \multirow[t]{2}{*}{ Média } \\
\hline & 15 & 17 & 19 & 21 & 23 & \\
\hline \multicolumn{7}{|c|}{ Rendimento da carcaça (\%) } \\
\hline Macho & 66,25 & 66,52 & 67,80 & 66,75 & 67,15 & 66,89 \\
\hline Fêmea & 66,15 & 65,42 & 68,33 & 68,29 & 68,59 & 67,36 \\
\hline Média $^{(2)}$ & 66,20 & 65,97 & 68,07 & 67,52 & 67,87 & \\
\hline \multicolumn{7}{|c|}{ Porcentagem de gordura abdominal (\%) } \\
\hline Macho & 3,98 & 3,17 & 3,58 & 2,81 & 2,79 & $3,27 b$ \\
\hline Fêmea & 4,65 & 4,57 & 4,18 & 4,20 & 4,17 & $4,36 \mathrm{a}$ \\
\hline Média ${ }^{(2)}$ & 4,32 & 3,87 & 3,88 & 3,50 & 3,48 & \\
\hline \multicolumn{7}{|c|}{ Porcentagem de peito $(\%)$} \\
\hline Macho & 28,01 & 29,45 & 28,69 & 29,66 & 28,91 & $28,95 b$ \\
\hline Fêmea & 30,75 & 29,48 & 30,18 & 29,97 & 29,62 & $29,99 \mathrm{a}$ \\
\hline Média & 29,38 & 29,46 & 29,43 & 29,82 & 29,27 & \\
\hline
\end{tabular}

${ }^{(1)}$ Médias seguidas de letras diferentes diferem entre si pelo teste de Tukey a $5 \%$ de probabilidade. ${ }^{(2)}$ Efeito linear. 


\section{Conclusões}

1. Os níveis de proteína bruta recomendados para frangos de corte machos e fêmeas, na fase de crescimento, são de $21,70 \%$ e $19,00 \%$, respectivamente.

2. Níveis de proteína abaixo desses valores diminuem o desempenho mesmo com a suplementação dos aminoácidos essenciais metionina, lisina, treonina e triptofano na ração.

\section{Referências}

ALBINO, L.F.T.; SILVA, S.H.M.; VARGAS JUNIOR, J.G.; ROSTAGNO, H.S. Níveis de metionina + cistina para frangos de corte de 1 a 21 e de 22 a 42 dias de idade. Revista Brasileira de Zootecnia, v.28, p.519-525, 1999.

BUYZE, J.; DECUYPERE L.; BERGHMAN, L.; KUHN, E.R.; VANDESAND, F. Effect of dietary protein content on episodic growth hormone secretion and heat production of male broiler chickens. British Poultry Science, v.33, p.1101-1109, 1992.

CAHANER, A.; PINCHASOV, Y.; NIR, I. Effects of dietary protein under high ambient temperature on body weight, breast meat yield, and abdominal fat deposition of broiler stocks differing in growth rate and fatness. Poultry Science, v.74, p.968-975, 1997.

CHENG, T.K.; HAMRE, M.L.; COON, C.N. Responses of broiler to dietary protein levels and amino acid supplementation to low protein diets at various environmental temperatures. Journal of Applied Poultry Research, v.6, p.18-33, 1997.

COSTA, F.G.P.; ROSTAGNO, H.S. ALBINO, L.F.T. Níveis dietéticos de proteína bruta para frangos de corte de 1 a 21 e 22 a 42 dias de idade. Revista Brasileira de Zootecnia, v.30, p.1498-1505, 2001.

DESCHEPPER, K.; DE GROTTE, G. Effect of dietary protein essential and non-essential amino acids on the performance of male broiler chickens. British Poultry Science, v.36, p.229-245, 1995.

DIAMBRA, O H.; McCARTNEY, M.G. The effect of low protein finisher diets on broiler males performance and abdominal fat. Poultry Science, v.64, p.2013-2015, 1995.

FISCHER, C. Use of amino acids to improve carcass quality of broilers. Feed Mix, v.2, p.17-20, 1994.

GONZALES, E. Ingestão de alimentos: mecanismos regulatórios. In: MACARI, M.; FURLAN, R.L.; GONZALES, E. (Ed.). Fisiologia aviária aplicada a frangos de corte. 2.ed. Jaboticabal: Funep, 2002. p.187-199.

HURWITZ, S.D.; SKLAN, H.; TALPAZ, H.; PLAVNIK, I. The effect of dietary level on the lysine and arginine requerimentes of growg chickes. Poultry Science, v.77, p.689-696, 1998.
JACKSON, S.; SUMMERS, J.D.; LEESON, S. Effect of dietary protein and energy on broiler carcass composition and efficiency of nutrient utilization. Poultry Science, v.61, p.2224-2231, 1982.

LEENSTRA, F.R. Effect of age, sex, genotype and environment on fat deposition in broiler chickens: a review. World's Poultry Science Journal, v.42, p.12-25, 1986.

LEESON, S. Nutrição e qualidade de carcaça de frangos de corte. In: CONFERÊNCIA APINCO DE CIÊNCIA E TECNOLOGIA AVÍCOLA, 1995, Curitiba. Anais. Curitiba: Apinco, 1995. p.111118.

LISBOA, J.S.; SILVA, D.J. Rendimento de carcaça de três grupos genéticos de frangos de corte alimentados com rações contendo diferentes teores de proteína. Revista Brasileira de Zootecnia, v.28, p.548-554, 1999.

McLEOD, J.A. Nutricional factores influencing carcass fat in broilers: a review. World's Poultry Science Journal, v.38, p.194-200, 1982. MORAN, J.R.; BUSHONG, E.T.; BILGILI, R.D. Reducing dietary crude protein for broilers while satisfying amino acid requirements by least-cost formulation: live performance, litter composition, and yield of fast-food carcass cuts at six weeks. Poultry Science, v.71, p.1687-1694, 1992.

OLOMU, J.M.; OFFIONG, S.A. The effects of different protein and energy levels $\mathrm{Nd}$ time of change from starter to finisher ration on performance of broiler chickens in the tropics. Poultry Science, v.59, p.828-835, 1980.

ROSTAGNO, H.S.; ALBINO, L.F.T.; DONZELE, LJ.L; GOMES, P.C.; FERREIRA, A.S.; OLIVEIRA, R.F.; LOPES, D.C. Tabelas brasileiras para aves e suínos: composição de alimentos e exigências nutricionais. Viçosa: UFV, 1996. 141p.

ROUSH, W.B. Na investigation of protein levels for broiler starter and finisher rations and the time of ration change by response surface methodology. Poultry Science, v.62, p.110-116, 1983.

SAKOMURA, N.K.; SILVA, R. Conceitos aplicáveis à nutrição de não ruminantes. Cadernos Técnicos da Escola de Vetrinária da UFMG, v.22, p.125-146, 1998.

SALMON, R.E.; CLASSEN, H.L.; McMILLAN, R.K. Effect of starter and finisher protein on performance, carcass grade and meat yield of broilers. Poultry Science, v.62, p.837-845, 1983.

SAS INSTITUTE (Cary, Estados Unidos). SAS user's guide: statistics, version 6. $12^{\text {th }}$ ed. Carry, 1996. 956p.

SCHUTTE, J.B.; PACK, M. Effects of dietary sulphur-containing amino acids on performance and breast meat deposition of broiler chicks during the growing and finishing phases. British Poultry Science, v.36, p.747-762, 1995.

SKLAN, D.; PLAVNIK, I. Interactions between dietary crude protein and essential amino acid intake on performance in broilers. British Poultry Science, v.43, p.442-449, 2002.

$\overline{\text { Recebido em } 24 \text { de junho de } 2003 \text { e aprovado em } 11 \text { de março de } 2004}$ 